\title{
is Research Square \\ Distribution of Leptospira Serogroups In Swine Herds In France, 2007 - 2017
}

\section{Jeanne Naudet}

ENS Lyon: Ecole normale superieure de Lyon

\section{Laurent Crespin}

INRAE: Institut National de Recherche pour l'Agriculture I'Alimentation et l'Environnement

Julien Cappelle

CIRAD

\section{Angeli Kodjo}

VetAgro Sup

Florence Ayral ( $\sim$ florence.ayral@vetagro-sup.fr)

VetAgro Sup https://orcid.org/0000-0002-7119-3765

\section{Research Article}

Keywords: Leptospira, pig, reproductive failure, micro-agglutination test, Australis, Icterohaemorrhagiae

Posted Date: August 23rd, 2021

DOI: https://doi.org/10.21203/rs.3.rs-764326/v1

License: (c) (1) This work is licensed under a Creative Commons Attribution 4.0 International License. Read Full License 


\section{Abstract}

Background: Leptospirosis is a widespread zoonotic disease caused by pathogenic Leptospira and is responsible for significant economic losses in porcine livestock. Knowledge of Leptospira serogroups and their distributions is important for evaluating the relevance of leptospirosis management measures, including the use of the prophylactic vaccine recently made available in France.

A retrospective study was conducted to determine the distribution of Leptospira serogroups. Pigs from across France presenting clinical signs suggestive of leptospirosis were tested by micro-agglutination test between 2007 and 2017. We used a weighted average to determine the serogroup distributions according to the MAT results, considering cross reactions.

Results: A total of 19,395 pig sera, mostly from Brittany, were tested, and $22.7 \%$ were found to be positive for at least one Leptospira serogroup. In analysing the 4346 seropositive results for which the putative infective serogroup could be defined, we found that two serogroups out of ten were much more frequent than the others: Australis (48.5\%) and Icterohaemorrhagiae (38.2 \%). Other serogroups, including Autumnalis, Panama, Ballum, Tarassovi, Sejroe, Grippotyphosa, Bataviae, and Pomona, were less common.

Conclusion: Although data from diagnostic laboratories are prone to selection bias, using such a large amount of data provides a relevant overview of Leptospira distribution in space and time. Extracting epidemiological information with a standardized approach could be used for surveillance and support prophylactic strategies. Along the last decade, provide protection against the serogroups Australis and Icterohaemorrhagiae could prevent most of the clinical porcine leptospirosis in France.

\section{Introduction}

Leptospirosis is a worldwide zoonotic disease of major importance caused by pathogenic spirochetes of the genus Leptospira. To date, 38 pathogenic Leptospira species have been described (composing subclades 1 and 2, previously referred to as pathogenic and intermediary Leptospira, respectively) (1). Among the currently known pathogenic Leptospira taxa, more than 300 serovars have been identified and classified into serogroups according to their antigenic similarities (2).

In both humans and other animals, Leptospira infection can cause mild or strong clinical signs or be asymptomatic. In swine, acute and chronic infections are described mainly in regards to the reproductive impairments (abortion, stillbirth, perinatal mortality) responsible for economic losses; however, deterioration of general condition is also described, including haemorrhage, haematuria, renal damage and death (3). Asymptomatic carriage also appears to occur in pigs, allowing for the undetected expansion and maintenance of the bacteria on farms (4).

Transmission generally occurs by contact with water spoiled by contaminated urine, in which the bacteria can curviva far covaral manthe (5) Tho main hosts of the Leptospira bacteria are rodents; however, other Loading [MathJax]/jax/output/CommonHTML/jax.js 
wild and domestic mammal species can also be involved in the transmission pathways. Because pig farming is mainly conducted indoors in France, contamination is most likely to occur via the introduction of an infected individual or through contact with commensal rodents. Furthermore, as close contact between animals can promote intra-herd transmission of the bacteria, the regulation that has recently mandated that pregnant sows be grouped together (Directive 2008/120/EC) could lead to an increased Leptospira incidence.

The incidence of Leptospira on pig farms in Europe remains unknown. However, epidemiological information has been extracted from data recorded in laboratories offering MAT for diagnostic purposes. According to these data, between $19 \%$ and $26 \%$ of tested pigs were seropositive in Italy, Germany and France (6-9). However, the inclusion criteria (e.g., the inclusion or not of pigs without clinical suspicion of infection) and the panel of serogroups included may vary among studies, leading to study variation in seroprevalence and limiting reliable comparisons of the results.

In addition, the previous studies did not report how the MAT results, including the cross sero-reactivity results, were managed (6-9). According to previous studies, MAT result interpretation is subjective and should consider possible cross reactions $(10,11)$. Chappel et al. 2004 recommended that in the presence of cross-reactions, the serogroup associated with the maximum titre should be considered the predominant serogroup. In addition, Miller et al. (2011) showed that the values of a single dilution titre vary among operators. Thus, a strict difference of two dilutions between the maximum titre and the others should be considered to account for this variability and ensure the putative infective serogroup is defined with sufficient evidence. As no consensus currently exists in the literature regarding the definition of the predominant serogroup, this paper suggests the use of weighted averages to report the serogroup distribution from large sets of MAT surveillance data.

Given that several mammalian species may act as reservoirs for swine leptospirosis, disease source control is complex. Vaccination may be a promising way to reduce the health and economic consequences of Leptospira infections. Vaccines provide protection against homologous or closely related but not heterologous serovars; therefore, particular attention should be paid to identifying relevant serovar antigen for vaccine development. In France, a swine vaccine has been commercialized since 2019 that protects against the following serogroups: Icterohaemorrhagiae, Australis, Grippotyphosa, Pomona and Tarassovi. However, a comprehensive survey of all serogroups circulating in swine herds in France is required to assess the relevance of including a given serogroup in a putative vaccine. The last such survey dates back to 2007 (6), and in light of the spatio-temporal variation in serogroup distribution observed in domestic animals $(12,13)$, updated data are required. This paper reports the results of a nationwide survey of the serogroups in swine herds in France.

\section{Materials And Methods}

For confirmatory diagnosis, 28,332 swine sera were collected by local veterinarians from pigs that chnumad cumntnme nnncictont with lontncnirosis. The samples were analysed by the "Laboratoire des Loading [MathJax]/jax/output/CommonHTML/jax.js 
Leptospires" (Marcy-l'Étoile, France) between October 2007 and April 2017 by a micro-agglutination test (MAT) to detect antibodies against a large panel of serogroups. Over the ten-year duration of the survey, the panel of serogroups has slightly varied. However, 19,395 sera were tested for the same serogroups listed here with their serovars in parentheses: Australis (munchen, australis, bratislava), Autumnalis (autumnalis, bim), Ballum (ballum), Bataviae (bataviae), Icterohaemorrhagiae (icterohaemorrhagiae, copenhageni), Grippotyphosa (grippotyphosa, vanderhoedoni), Panama (panama, mangus), Pomona (pomona, mozdok), Sejroe (sejroe, saxkoebing, hardjo, wolffi) and Tarassovi (tarassovi). This test was performed using a serum dilution series from 1:100 to 1:6400, and a titre $\geq 1: 100$ was considered suggestive of a past or current infection.

To avoid the limitations of interpretation related to cross reactions and the subjective nature of MAT interpretation (11), we applied the following criteria:

(1) A single predominant serogroup was defined by either a titre $\geq 1: 100$ against a single serogroup or a two-fold or greater difference between the highest titre and the other titres. In both cases, a value of 1 , associated with a high certainty of incrimination, was assigned to the predominant serogroup.

(2) Equally predominant serogroups were defined based on the detection of titres $\geq 1: 100$ against two or three serogroups with equal titres or a less than two-fold difference between the highest titre and the next highest titre. The presence of two or three predominant serogroups most likely resulted from cross reactions $(14,15)$. Thus, values of 0.5 or 0.33 were allotted to the two or three predominant serogroups, respectively.

(3) Serological profiles with more than 3 predominant serogroups were considered uninformative and were removed from the analysis as these profiles likely resulted from cross-reactive IgM antibodies at the onset of infection $(11,16,17)$.

The frequency of each serogroup was computed as a weighted average by summing the numbers of positive swine sera for the serogroup, weighting by the values defined above, and dividing by the total number of seropositive sera (18).

To assess potential variation in the serogroup distribution, mainland France was studied at the "département" scale (administrative unit). The tested pigs per "département" were visualized in Quantum GIS (QGIS version 2.18) with the background map from IGN GEOFLA®.

\section{Results}

Of the 19,395 tested swine sera, 4398 (22.7\%) were positive for at least one serogroup, including 2608 that were positive for a single serogroup, 1410 that were positive for two serogroups and 328 that were positive for three serogroups. Using the three criteria defined above, fifty-two MAT results $(1.2 \%$ of the positive results) were sero-reactive against more than three serogroups and were therefore discarded from tho analvcic $\Lambda n$ analvcic 11 cino $n n$ lv the sera for which a single serogroup was unambiguously Loading [MathJax]/jax/output/CommonHTML/jax.js 
identified would have been based on 2608 positive samples (59.3\% of the samples testing positive), whereas our analysis was based on 4346 positive samples ( $98.8 \%$ of the samples testing positive), conferring us a large increase in statistical power. The predominant serogroups were Australis and Icterohaemorrhagiae, which had frequencies of $48.5 \%$ and $38.2 \%$, respectively, followed by Autumnalis (6.1\%), Panama (5\%), Ballum (1.2\%), Tarassovi (0.5\%), Sejroe (0.2\%), Grippotyphosa (0.2 \%), Bataviae (0.1\%), and Pomona (<0.1\%) (Fig. 1).

The sera originated from a total of 2326 farms all across France, among which 1123 (48\%) had at least one seropositive individual. These farms represented $87 \%$ of the tested "départements" in mainland France.

The numbers of tested animals were higher in "départements" of West France than in those of other regions. The seropositivity against the predominant serogroups Australis and Icterohaemorrhagiae and other serogroups was homogeneous across the country: no pattern was evident in the spatial distribution of seropositivity against any one serogroup (Fig. 2).

\section{Discussion}

Employing a retrospective approach, our study shows that antibodies against pathogenic Leptospira serogroups are frequently detected on French pig farms. In addition, two serogroups were found to be detected much more frequently than the others: Australis and Icterohaemorrhagiae, with frequencies of $48.5 \%$ and $38.2 \%$, respectively. These high frequencies suggest that despite potential biases linked to sample selection and/or the approach used to define the putative infecting serogroup (discussed below), most Leptospira infections in French swine originated from only two serogroups out of the ten detected in this study.

The predominant sero-reactivity against Leptospira from the serogroups Australis and Icterohaemorrhagiae in pigs is consistent with previous data reported in France (6). It suggests the absence of any changes in the epidemiological context related to Leptospira strain distribution. A recent study in Italy that included pigs with clinical suspicion of leptospirosis was implemented using an eightserovar panel, including seven that were common with our panel, and identified Australis and Pomona as the most frequently detected serogroups (9). However, caution is warranted in interpreting this consistency because the previous studies did not report how MAT results with cross sero-reactivity were managed; it is likely that the approach differed from the one in the present study. These observations support the need of a standardized approach when performing MAT surveillance data analysis.

For the MAT, even when a threshold of positivity of 1:100 is employed, recently infected, chronically infected or previously exposed individuals cannot be clearly distinguished (4). However, because we were chiefly interested in the distribution of the Leptospira serogroups at a large geographical scale, any evidence of past infections was relevant to describing the distribution of the serogroups circulating in pigs. In addition, serogroups Australis and Icterohaemorrhagiae were predominant each year from 2007 
to 2017 in our dataset, which suggests that misclassifying past or current infections would have limited effects on our results.

Most of the samples came from Brittany, which is more intensive pig farming area than other regions in France. However, the serogroup distribution was similar among regions. The samples we used originated from swine herds with a clinical suspicion of leptospirosis; thus, we can conclude that throughout France, herds with reproductive disorders that are exposed to Leptospira are most likely exposed to the Australis and Icterohaemorrhagiae serogroups. A broader survey including non-symptomatic herds could clarify the relationship between Leptospira serogroup exposure and reproductive failure. Nonetheless, within the pig isolates related to the serogroup Australis, some are more likely to be associated with disease (19), and Australis exposure in pigs should be seriously considered as the potential cause of reproductive failure.

Herd management of leptospirosis may rely on animal reservoir control. Rattus norvegicus is a frequent commensal rodent in livestock buildings and a selective carrier of Leptospira from the serogroup Icterohaemorrhagiae $(20,21)$. Thus, rats may be incriminated to some extent in Icterohaemorrhagiae pig exposure and could be reduced through rat management. As no selective carriers of Leptospira from the serogroup Australis have been described among commensal rodents, pig themselves could be the main maintenance host in the context of pig farming, as suggested by Ellis (2015). Leptospirosis management through the culling of Leptospira carriers is limited by the low specificity and sensitivity of the MAT in individuals (22). According to our results, a vaccine providing protection against the serogroups Australis and Icterohaemorrhagiae may greatly reduce the incidence of the disease, as more than $50 \%$ of the seropositive pigs were exposed to at least one of these serogroups. Pending more efficient sanitary measures, systematizing the prophylactic vaccination of pigs in farms appears to be a promising option for disease management and can be expected to reduce the health consequences in most cases in the future.

As the serogroups Australis and Icterohaemorrhagiae are also pathogenic for humans, infected pig populations represent a potential cause of occupational disease, especially for breeders or slaughterhouse staff $(23,24)$. Following a One Health approach, leptospirosis management in pig populations may contribute to the protection of human population and to the mitigation of Leptospira persistence and transmission in the country.

\section{Conclusion}

The distribution of Leptospira serogroups may change in space and time. Analyses of data from diagnostic laboratories are useful for obtaining an indication of this distribution in a region or a country and over time. Our results shows that over the 10-year study period, most Leptospira infections in French swine originated from only two serogroups out of the ten used for the analysis, Australis and Icterohemorrhagiae. This information should be considered to support future prophylactic measures. 
In Europe, numerous laboratories have published interpreted MAT results. However, there is no consensus on the panel of serovars to be included, positive threshold and serogroup determination in case of crossreactions leading to none comparable results from a study to another. Finally, this is an appeal to veterinary laboratories from Western Europe to standardize their approach when performing MAT surveillance data analysis. Based on our results and previously published ones, further MAT surveillance data analysis should be supported by MAT provided with at least a common set of serovars belonging to the serogroups Australis, Ballum, Bataviae, Icterohaemorrhagiae, Grippotyphosa, Panama, Pomona, Sejroe and Tarassovi and a weighted average approach to determine the serogroup distributions, considering cross reactions.

\section{Abbreviations}

MAT: Micro Agglutination Test, AUS: Australis, AUT: Autumnalis, BAT: Bataviae, GRI: Grippotyphosa, ICT: Icterohaemorrhagiae, PAN: Panama, POM: Pomona, PYR: Pyrogenes, TAR: Tarassovi, SJ: Sejroe.

\section{Declarations}

\section{Acknowledgements}

The authors thank the technicians who provided their technical support in the laboratory performing the MAT, between 2007 and 2017. We are also grateful to VetAgro Sup for funding the study.

\section{Funding}

This work was supported by VetAgro Sup, Marcy L’Etoile, France [Agriculture Ministry Funding].

\section{Availability of data and materials}

The datasets used and/or analysed during the current study are available from the corresponding author on reasonable request.

\section{Authors' contributions}

FA made substantial contributions to the concept and design of the study, interpreted the results and revised the manuscript critically. LC and JC contributed to the concept and design of the study and revised the manuscript critically. JC was involved in the spatial data analysis. JN wrote the manuscript and constructed the figures. AK provided the data from the Laboratoire des Leptospires and revised the manuscript.

\section{Ethic approval and consent to participate}

The present research does not include experimental data and all laboratory analysis were performed on data from previous examinations of swine for routine diagnosis. The Ethical Committee was respected 
and has confirmed that approval was not required in this case.

\section{Consent for publication}

Not applicable

\section{Competing of interest}

The authors declare that they have no competing interests.

\section{References}

1. Vincent AT, Schiettekatte O, Goarant C, Neela VK, Bernet E, Thibeaux R, et al. Revisiting the taxonomy and evolution of pathogenicity of the genus Leptospira through the prism of genomics. PLoS Negl Trop Dis 23 mai. 2019;13(5):e0007270.

2. Levett PN. Systematics of Leptospiraceae. In: Adler B, éditeur. Leptospira and Leptospirosis [Internet]. Berlin, Heidelberg: Springer; 2015 [cité 10 mai 2020]. p. 11-20. (Current Topics in Microbiology and Immunology). Disponible sur: https://doi.org/10.1007/978-3-662-45059-8_2.

3. Bolin CA. Diagnosis of leptospirosis in swine. Swine Health Prod Off J Am Assoc Swine Pract USA [Internet]. 1994 [cité 13 mai 2019]; Disponible sur: http://agris.fao.org/agris-search/search.do? recordID =US9519052.

4. Ellis WA. Animal leptospirosis. Curr Top Microbiol Immunol. 2015;387:99-137.

5. Andre-Fontaine G, Aviat F, Thorin C. Waterborne Leptospirosis: Survival and Preservation of the Virulence of Pathogenic Leptospira spp. in Fresh Water. Curr Microbiol juill. 2015;71(1):136-42.

6. André-Fontaine G. Leptospirosis in domestic animals in France: serological results from 1988 to 2007. Rev Sci Tech Int Off Epizoot déc. 2016;35(3):913-23.

7. Bertelloni F, Cilia G, Turchi B, Pinzauti P, Cerri D, Fratini F. Epidemiology of leptospirosis in NorthCentral Italy: Fifteen years of serological data (2002-2016). Comp Immunol Microbiol Infect Dis 1 août. 2019;65:14-22.

8. Strutzberg-Minder K, Tschentscher A, Beyerbach M, Homuth M, Kreienbrock L. Passive surveillance of Leptospira infection in swine in Germany. Porc Health Manag [Internet]. 27 mars 2018 [cité 10 mai 2020];4. Disponible sur: https://www.ncbi.nlm.nih.gov/pmc/articles/PMC5872537/.

9. Tagliabue S, Figarolli BM, D'Incau M. Serological surveillance of Leptospirosis in Italy: twoyear national data (2010-2011). Vet Ital. 2016;(52(2)):129-39.

10. Chappel RJ, Goris M, Palmer MF, Hartskeerl RA. Impact of Proficiency Testing on Results of the Microscopic Agglutination Test for Diagnosis of Leptospirosis. J Clin Microbiol 1 déc. 2004;42(12):5484-8.

11. Miller MD, Annis KM, Lappin MR, Lunn KF. Variability in Results of the Microscopic Agglutination Test in Dogs with Clinical Leptospirosis and Dogs Vaccinated against Leptospirosis. J Vet Intern Med. 1 
12. Ayral F, Bicout DJ, Pereira H, Artois M, Kodjo A. Distribution of Leptospira Serogroups in Cattle Herds and Dogs in France. Am J Trop Med Hyg 1 oct. 2014;91(4):756-9.

13. Stokes JE, Kaneene JB, Schall WD, Kruger JM, Miller R, Kaiser L, et al. Prevalence of serum antibodies against six Leptospira serovars in healthy dogs. J Am Vet Med Assoc 1 juin. 2007;230(11):1657-64.

14. Ayral F, Djelouadji Z, Raton V, Zilber A-L, Gasqui P, Faure E, et al. Hedgehogs and Mustelid Species: Major Carriers of Pathogenic Leptospira, a Survey in 28 Animal Species in France (20122015). PLOS ONE. sept 2016;28(9):e0162549. 11(.

15. Kusum M, Boonsarthorn N, Biaklang M, Sina U, Sawanpanyalert P, Naigowit P. Comparison of leptospiral serovars identification by serology and cultivation in northeastern region, Thailand. J Med Assoc Thail Chotmaihet Thangphaet août. 2005;88(8):1098-102.

16. Levett PN. Leptospirosis. Clin Microbiol Rev avr. 2001;14(2):296-326.

17. Lupidi R, Cinco M, Balanzin D, Delprete E, Varaldo PE. Serological follow-up of patients involved in a localized outbreak of leptospirosis. J Clin Microbiol avr. 1991;29(4):805-9.

18. Sokal RR, Rohlf FJ. Biometry: the principles and practice of statistics in biological research [Internet]. 3rd ed. New York: W.H. Freeman; 1995. https://trove.nla.gov.au/work/10262434. [cité 15 juin 2020. Disponible sur.

19. Ellis WA, Montgomery JM, Thiermann AB. Restriction endonuclease analysis as a taxonomic tool in the study of pig isolates belonging to the Australis serogroup of Leptospira interrogans. J Clin Microbiol mai. 1991;29(5):957-61.

20. Ayral F, Zilber A-L, Bicout DJ, Kodjo A, Artois M, Djelouadji Z. Distribution of Leptospira interrogans by Multispacer Sequence Typing in Urban Norway Rats (Rattus norvegicus): A Survey in France in 2011-2013. PLOS ONE. oct 2015;8(10):e0139604. 10(.

21. Thiermann AB. The Norway rat as a selective chronic carrier of Leptospira icterohaemorrhagiae. J Wild Dis janv. 1981;17(1):39-43.

22. Ellis WA. 03.01.12_Leptospirose. In: Manual of Diagnostic Tests and Vaccines for Terrestrials Animals [Internet]. OIE; 2018 [cité 12 avr 2019]. p. 503-16. Disponible sur: http://www.oie.int/fileadmin/Home/fr/Health_standards/tahm/3.01.12_LEPTO.pdf.

23. Mirambo MM, Mgode GF, Malima ZO, John M, Mngumi EB, Mhamphi GG, et al. Seropositivity of Brucella spp. and Leptospira spp. antibodies among abattoir workers and meat vendors in the city of Mwanza, Tanzania: A call for one health approach control strategies. PLoS Negl Trop Dis. 2018;12(6):e0006600.

24. Thornley CN, Baker MG, Weinstein P, Maas EW. Changing epidemiology of human leptospirosis in New Zealand. Epidemiol Infect févr. 2002;128(1):29-36.

\section{Figures}




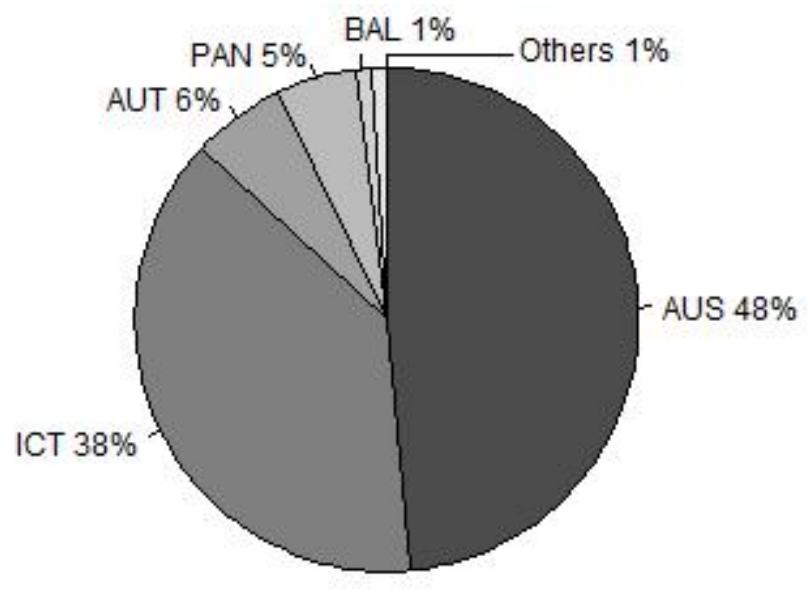

\section{Figure 1}

The distribution of Leptospira serogroups among 4346 swine samples from 1123 herds with suspected clinical leptospirosis. Australis (AUS), Autumnalis (AUT), Bataviae (BAT), Grippotyphosa (GRI), Icterohaemorrhagiae (ICT), Panama (PAN), Pomona (POM), Pyrogenes (PYR), Tarassovi (TAR) and Sejroe (SJ).

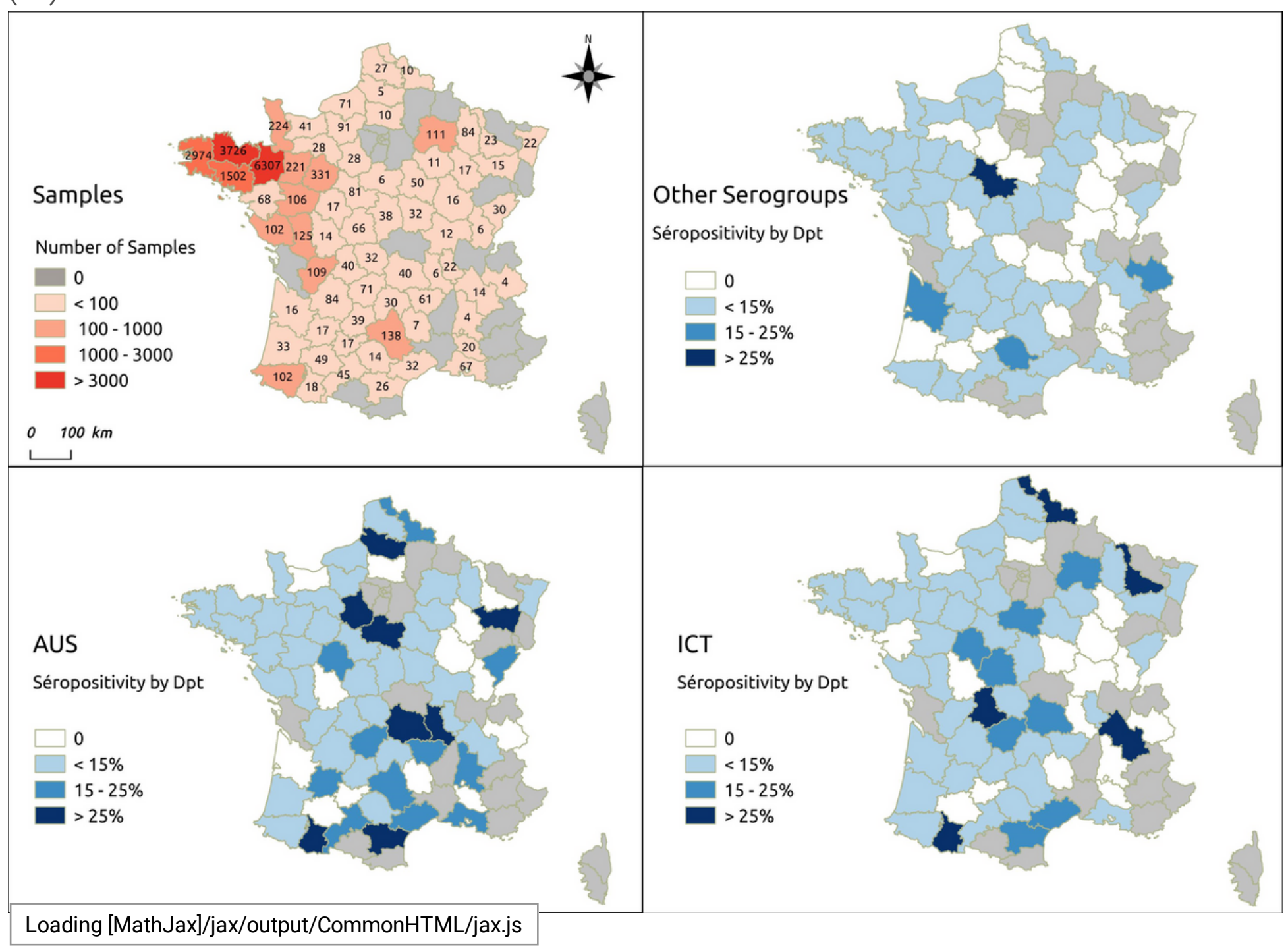




\section{Figure 2}

The spatial distribution of the swine tested and the seropositivity against Australis, Icterohaemorrhagiae and other serogroups per "département" (administrative district) in mainland France. 